\title{
Physician barriers to population-based, fecal occult blood test-based colorectal cancer screening programs for average-risk patients
}

\author{
S Elizabeth McGregor $\mathrm{PhD}^{1}$, Robert J Hilsden $\mathrm{MD} \mathrm{PhD}^{2}$, Huiming Yang $\mathrm{MD}^{3}$
}

SE McGregor, RJ Hilsden, $H$ Yang. Physician barriers to population-based, fecal occult blood test-based colorectal cancer screening programs for average-risk patients Can J Gastroenterol 2010;24(6):359-364.

BACKGROUND: Colorectal cancer (CRC) screening is an efficacious but underused means to reduce the burden of CRC. Population-based CRC screening programs are currently being implemented in Canada and physicians are key partners in increasing screening uptake. The current study identified physician attitudes and barriers that need to be addressed by provincial programs.

METHODS: A mailed survey of primary care physicians in Alberta.

RESULTS: The survey response rate was $42.4 \%$ (806 of 1903). The majority of physicians suggested CRC screening as part of a routine periodic examination; however, the approach to test selection and the type of tests recommended varied by geographical region. The majority of physicians agreed $(48 \%)$ or strongly agreed $(36 \%)$ that a provincewide screening program is the best approach to reducing mortality from CRC. However, there were many serious concerns identified - the most common was endoscopic capacity for follow-up of patients with a positive fecal occult blood test (FOBT), which was cited by $55 \%$ to $69 \%$ of the physicians surveyed. The barriers to three commonly available tests (FOBT, flexible sigmoidoscopy and colonoscopy) varied according to health region, and the types of barriers identified varied according to the specific test.

INTERPRETATION: Screening for CRC is gradually being accepted among primary care physicians in Alberta. A key finding of the present descriptive study was the regional variation in practices, perceived barriers and concerns about provincial population-based screening programs based on FOBT as the primary screening test. Provincial programs will need to address the issue of endoscopic capacity and perceived barriers to FOBT to gain primary care physician acceptance of FOBT-based CRC screening programs.

Key Words: Colorectal cancer; Health surveys; Mass screening; Primary care

$\mathrm{C}$ olorectal cancer (CRC) is an important public health problem and the second leading cause of death from cancer among Canadians, with an estimated 22,000 cases and approximately 9100 deaths expected in Canada in 2009 (1). Although there is strong evidence that screening can reduce the incidence of and mortality from CRC, screening rates remain low (2-5). Indeed, CRC screening has been identified as a high-impact, cost-effective, underused service (6) that merits strong consideration for incorporation into medical practice (7).
Les obstacles auxquels se heurtent les pédiatres pour procéder à des programmes de dépistage du cancer colorectal en population par recherche de sang occulte dans les selles chez les patients à risque moyen

HISTORIQUE : Le dépistage du cancer colorectal (CCR) est un moyen efficace mais sous-utilisé de réduire le fardeau du CCR. Les programmes de dépistage du CCR en population sont en voie de mise en œuvre au Canada, et les médecins sont des partenaires clés pour en accroître l'application. La présente étude a permis de déterminer les attitudes des médecins et les obstacles auxquels ils se heurtent et dont doivent tenir compte les programmes provinciaux.

MÉTHODOLOGIE : Questionnaire postal auprès des médecins de premier recours de l'Alberta.

RÉSULTATS : Le taux de réponse au questionnaire s'est élevé à 42,4\% (806 sur 1 903). La majorité des médecins ont suggéré que le dépistage du CCR fasse partie de l'examen périodique régulier, mais la démarche de sélection du test et le type de tests recommandés variaient selon la région géographique. La majorité des médecins étaient en accord (48\%) ou fortement en accord (36 \%) avec le fait qu'un programme de dépistage provincial représente la meilleure approche pour réduire la mortalité causée par le CCR. Cependant, de nombreuses inquiétudes importantes étaient relevées, la principale étant la capacité de suivre en endoscopie les patients dont la recherche de sang occulte dans les selles (RSOS) est positive, citée par $55 \%$ à $69 \%$ des médecins sondés. Les obstacles aux trois tests courants (RSOS, sigmoïdoscopie flexible et coloscopie) variaient selon la région sanitaire, tandis que le type d'obstacles repérés variait selon le test.

INTERPRÉTATION : Le dépistage du CCR est graduellement accepté chez les médecins de premier recours de l'Alberta. La variation régionale des pratiques, des obstacles perçus et des préoccupations au sujet des programmes de dépistage en population d'après le choix de la RSOS comme test de dépistage primaire constitue une constatation clé de la présente étude descriptive. Les programmes provinciaux devront tenir compte de la capacité endoscopique et des obstacles perçus liés à la RSOS pour que les médecins de premier recours acceptent les programmes de dépistage du CCR au moyen de la RSOS.

${ }^{1}$ Population Health Research, Alberta Health Services Cancer Care; ${ }^{2}$ Departments of Medicine and Community Health Sciences, University of Calgary; ${ }^{3}$ Alberta Health Services Population and Public Health, Calgary, Alberta

Correspondence: Dr S Elizabeth McGregor, Population Health Research, Alberta Health Services Cancer Care, 1331 29th Street NW, Calgary,

Alberta T2N 4N2. Telephone 403-521-3754, fax 403-270-8003, e-mail elizabeth.mcgregor@albertahealthservices.ca

Received for publication August 11, 2009. Accepted October 6, 2009 
that annual or biennial FOBT screening was efficacious in reducing CRC mortality from $15 \%$ to $33 \%$. The Canadian Association of Gastroenterology (13) recommended the establishment of CRC screening programs, with choices for testing determined by patient preference, current evidence and local resources. More recently, the province of Alberta issued a clinical practice guideline (14) that recommends options for testing, including annual FOBTs.

A government of Canada committee recommended the implementation of FOBT-based screening programs in 2002 (15). To date, at least four provinces in Canada (Ontario, Manitoba, Alberta and Nova Scotia) have announced plans to implement population-based CRC screening programs with the FOBT as the primary screening test offered to asymptomatic, average-risk adults 50 years of age and older.

Physicians are key partners in population-based screening programs (16) because physician recommendation is a strong predictor of acceptance of CRC screening (17-19). Canadian physicians have been encouraged to screen patients for CRC since $2001(10,20,21)$. High provider adherence to CRC screening guidelines is a critical assumption in models supporting the cost effectiveness of CRC screening (22).

The purpose of the present survey was to determine attitudes toward CRC screening among primary care physicians in Alberta to identify key issues that need to be addressed in the implementation of province-wide screening; to compare attitudes and barriers according to health region; to assess their response to the newly announced, province-wide screening program; and to compare changes in attitudes and barriers since 2002, when a similar survey was conducted.

\section{METHODS}

Data were collected from January through May 2008 using a mailed survey. The entire target population comprised all licensed primary care physicians in active clinical practice in Alberta for whom CRC screening was relevant. A random sample of primary care physicians from each of three geographical areas, defined by regional health authority boundaries in place in December 2007, was selected from a database of currently licensed physicians that was purchased from the College of Physicians and Surgeons of Alberta. The three geographical regions were the Calgary Health Region (CHR, population 1.3 million), the Capital Health Region (Capital, population 1.1 million) and the remainder of the province (nonmetropolitan health regions, population 1.1 million). The total sample size was 2191 .

The structured questionnaire, a booklet consisting of 26 questions, ascertained information on current approaches to CRC screening, demographic and practice characteristics, opinions regarding CRC screening and perceived barriers to FOBT, flexible sigmoidoscopy and colonoscopy as screening tests for CRC. Definitions of average risk, defined as a person without a personal or family history of adenomatous polyps or CRC, and without a condition (eg, ulcerative colitis or Crohn's disease) that would predispose them to the development of CRC, and screening FOBTs were provided. A short description of the plans to implement a province-wide CRC screening program over the next five years with annual FOBT as the primary screening test was provided.

The study package - including a cover letter, a reply card physicians could return to indicate why they would not be completing the survey, the questionnaire and a self-addressed, postage-paid envelope - was mailed to all physicians selected for the study. An incentive (a draw for one of $10 \$ 150$ gift certificates at a retail chain of bookstores) was offered to physicans who returned a completed survey. Two follow-up mailings, consisting of a complete study package with a different cover letter for each follow-up mailing, were sent to nonresponders. The survey was pilot tested using a sample of 30 primary care physicians.

The usual screening practices, barriers to potential screening tests and opinions regarding CRC screening are described. The percentages were weighted for the three geographical health regions sampled. $\chi^{2}$ tests were used to test for differences according to geographical region. Region-specific estimates are presented if significant regional variation was present (based on $\mathrm{P}<0.05$ ).

The study was approved by the Conjoint Health Research Ethics Board of the University of Calgary (Calgary, Alberta) and the Research Ethics Board of the Alberta Cancer Board.

\section{RESULTS}

The response rate was 42.4\% (806 of 1903) after excluding those who were unreachable ( $\mathrm{n}=45$ of 2191 [2.1\%]), retired/deceased $(n=61$ of $2191[2.8 \%])$ or for whom the topic was not relevant $(n=182[8.3 \%])$.

Comparison of respondents and nonrespondents showed that respondents were representative of Alberta nonspecialist physicians with respect to geographical region, sex and College of Family Physicians certification (data not shown). The characteristics of physicians who completed the survey are presented in Table 1.

\section{Usual approach to CRC screening}

There was considerable regional variation in the usual approach to CRC screening for average-risk patients (Table 2). The majority of physicians suggested that CRC screening should be a part of the examination; however, the approach to test selection and the type of tests recommended varied according to geographical region. CHR physicians were most likely to offer options for testing, while physicians from other regions were more likely to recommend a specific test. The most common options for testing were FOBTs and colonoscopy, with more than $96 \%$ of physicians including FOBT as an option. Among physicians who recommended a specific test, FOBT was most commonly recommended; however, $39 \%$ of physicians in the CHR recommended colonoscopy as the primary screening test.

The majority of respondents (78.6\%) indicated that there was a need for print resources in their practice to help educate patients and their families about CRC screening. Many physicians would refer patients who wanted more information about CRC screening to a Web site ( $89.2 \%$ ), a ' $1-800$ ' telephone number $(61.0 \%)$ or a nurse-led educational session $(61.8 \%)$, if they were available.

\section{Potential concerns regarding provincial screening programs} The majority of physicians agreed (48\%) or strongly agreed $(36 \%)$ that a province-wide screening program is the best approach to reducing mortality from CRC. However, there were a number of serious concerns identified, the most common being endoscopic capacity for follow-up of patients with a positive FOBT, followed by patients' general lack of awareness 
TABLE 1

Characteristics of respondents $(n=806)$

\begin{tabular}{|c|c|c|}
\hline & $\mathrm{n}^{*}$ & $\%$ (weighted by region) \\
\hline \multicolumn{3}{|l|}{ Age group, years } \\
\hline $25-34$ & 135 & 16.6 \\
\hline $35-49$ & 350 & 43.4 \\
\hline $50-64$ & 281 & 34.8 \\
\hline \multicolumn{3}{|l|}{ Sex } \\
\hline Male & 453 & 53.3 \\
\hline Female & 353 & 46.7 \\
\hline \multicolumn{3}{|l|}{ University appointment } \\
\hline Yes & 175 & 21.5 \\
\hline No & 624 & 78.5 \\
\hline \multicolumn{3}{|l|}{ Years in practice } \\
\hline$<5$ & 138 & 17.3 \\
\hline $5-10$ & 116 & 14.5 \\
\hline $11-15$ & 118 & 4.3 \\
\hline$>15$ & 434 & 53.9 \\
\hline \multicolumn{3}{|l|}{ Practice setting } \\
\hline Solo & 90 & 11.3 \\
\hline Group & 649 & 80.0 \\
\hline Other & 60 & 8.7 \\
\hline \multicolumn{3}{|c|}{ Use an electronic medical record } \\
\hline Yes & 540 & 65.8 \\
\hline No & 258 & 34.2 \\
\hline \multicolumn{3}{|c|}{ Belong to a primary care network } \\
\hline Yes & 472 & 61.0 \\
\hline No & 330 & 39.0 \\
\hline Patients per week, mean & 781 & 128 \\
\hline \multicolumn{3}{|c|}{ Choice of screening test if they themselves were to be screened for CRC } \\
\hline None & 9 & 1.1 \\
\hline Colonoscopy & 414 & 51.5 \\
\hline Colonoscopy and FOBT & 62 & 7.8 \\
\hline FOBT & 190 & 23.4 \\
\hline CT colonography & 56 & 6.9 \\
\hline Other, including multiple & 82 & 9.4 \\
\hline
\end{tabular}

*Sum differs from 806 due to missing information. CRC Colorectal cancer; CT Computed tomography; FOBT Fecal occult blood test

about CRC screening (Table 3). Concern about FOBTs as the primary screening test was considered to be serious in the CHR but less so in the other two geographical regions.

Reported access to colonoscopy varied considerably according to geographical region, with physicians in the CHR reporting longer wait times for patients referred for all types of colonoscopies (Table 4). Wait times were shortest for physicians in the nonmetropolitan health region.

Perceived barriers to potential CRC screening tests

The perceived barriers to three commonly available tests (FOBT, flexible sigmoidoscopy and colonoscopy) are shown in Table 5. Patient-related barriers were common, particularly for colonoscopy. Barriers related to test characteristics were also common but the actual test characteristic differed according to the type of test. The potential to miss cancers was a major barrier for FOBT and less so for flexible sigmoidoscopy. Too many false positives were also a concern for FOBT. The potential for complications was the major barrier to colonoscopy. Lack of efficacy evidence was considered by some physicians to be a barrier to FOBT and flexible sigmoidoscopy, but not to colonoscopy.
TABLE 2

Usual approach to colorectal cancer (CRC) screening for average-risk patients

\begin{tabular}{lccc}
\hline $\begin{array}{l}\text { Usual approach to average-risk patient } \\
\text { with no symptoms or concerns about }\end{array}$ & \multicolumn{3}{c}{$\begin{array}{c}\text { Physicians who selected each } \\
\text { approach according to }\end{array}$} \\
\cline { 2 - 4 } $\begin{array}{l}\text { CRC who present for a routine check } \\
\text { up* }\end{array}$ & $\begin{array}{c}\text { CHR } \\
(\mathbf{n}=\mathbf{2 6 2})\end{array}$ & $\begin{array}{c}\text { Capital } \\
(\mathbf{n}=\mathbf{2 3 1})\end{array}$ & $\begin{array}{c}\text { Nonmetro } \\
(\mathbf{n}=\mathbf{3 1 3})\end{array}$ \\
\hline $\begin{array}{l}\text { Do not raise issue } \\
\text { Discuss, see if patient wants } \\
\text { to pursue }\end{array}$ & 21.1 & 1.4 & 6.0 \\
$\begin{array}{l}\text { Suggest screening as part of routine } \\
\text { examination }\end{array}$ & 76.3 & 16.9 & 18.5 \\
& & & \\
\end{tabular}

examination

Physicians who selected each approach according to

\begin{tabular}{|c|c|c|c|}
\hline \multirow{2}{*}{$\begin{array}{l}\text { Usual approach to screening test } \\
\text { selection for an average-risk patient* }\end{array}$} & \multicolumn{3}{|c|}{ geographical region, $\%$} \\
\hline & CHR & Capital & Nonmetro \\
\hline $\begin{array}{l}\text { Recommend a specific screening test } \\
(\mathrm{n}=422)^{\dagger}\end{array}$ & 39.0 & 65.2 & 55.0 \\
\hline Fecal occult blood test (FOBT) & 57.4 & 95.3 & 84.2 \\
\hline Colonoscopy & 38.6 & 1.3 & 11.7 \\
\hline FOBT and colonoscopy & 3.0 & 1.3 & 2.3 \\
\hline $\begin{array}{l}\text { Recommend several options that } \\
\text { include the following tests }{ }^{\dagger}(n=364)\end{array}$ & 59.8 & 33.9 & 42.1 \\
\hline FOBT & 96.8 & 100.0 & 96.2 \\
\hline Flexible sigmoidoscopy & 25.8 & 46.2 & 37.4 \\
\hline Air-contrast barium enema & 30.3 & 47.4 & 29.8 \\
\hline Colonoscopy & 97.4 & 84.6 & 87.8 \\
\hline $\begin{array}{l}\text { Computed tomography } \\
\text { colonography (virtual colonoscopy) }\end{array}$ & 23.9 & 2.6 & 3.8 \\
\hline Do not recommend screening $(n=14)$ & 1.2 & 0.9 & 2.9 \\
\hline
\end{tabular}

Health care resource barriers were the most common barriers for the structural examinations (flexible sigmoidoscopy and colonoscopy) and were highest for colonoscopy (Table 5). Almost all physicians indicated at least one resource barrier for colonoscopy, with long wait times being the most common barrier.

The percentage of barriers cited by physicians varied according to geographical region. Fewer physicians practicing in nonmetropolitan geographical regions reported barriers than physicians practicing in major urban centres (ie, CHR, Capital).

Comparisons with the previous survey regarding opinions about CRC screening

Table 6 compares responses to the current survey with those from a mailed survey of Alberta primary care physicians that was conducted in 2002 (23) using essentially the same methods. Respondents in the 2002 survey were less likely to be 50 years of age or older (32.1\% in 2002 versus $40.1 \%$ in 2008), more likely to be male $(60.5 \%$ in 2002 versus $53.3 \%$ in 2008), and less likely to have been in practice for less than five years $(13.6 \%$ in 2002 versus $17.3 \%$ in 2008$)$ or more than 15 years $(50.8 \%$ in 2002 versus $53.9 \%$ in 2008). The majority of physicians in both surveys were in group practice $(80.2 \%$ in 2002 versus $80.0 \%$ in 2008).

Respondents to the 2008 survey were more supportive of CRC screening than respondents to the 2002 survey (Table 6). The majority of respondents to the 2008 survey considered 
TABLE 3

Potential concerns regarding a provincial colorectal cancer screening program with the fecal occult blood test (FOBT) as the primary screening test according to health region

\begin{tabular}{|c|c|c|c|c|c|c|c|c|c|}
\hline \multirow{2}{*}{$\begin{array}{l}\text { How much, if at all, do you perceive the following to } \\
\text { be a concern? }\end{array}$} & \multicolumn{3}{|c|}{ Serious concern } & \multicolumn{3}{|c|}{ Moderate concern } & \multicolumn{3}{|c|}{ No concern } \\
\hline & CHR & Capital & Nonmetro & CHR & Capital & Nonmetro & CHR & Capital & Nonmetro \\
\hline $\begin{array}{l}\text { Endoscopic capacity for follow-up of patients with } \\
\text { positive FOBTs }(n=797)(P=0.001)^{*}\end{array}$ & 55.2 & 68.6 & 58.3 & 39.1 & 28.8 & 32.2 & 5.7 & 2.6 & 9.4 \\
\hline $\begin{array}{l}\text { Patients' general lack of awareness and knowledge } \\
\text { about colorectal screening }(n=796)(P=0.3)^{\star}\end{array}$ & 31.8 & 25.9 & 31.9 & 59.4 & 61.8 & 60.3 & 8.8 & 12.3 & 7.8 \\
\hline FOBT as the primary screening test $(n=789)(P<0.001)^{*}$ & 28.2 & 10.5 & 17.5 & 38.6 & 33.3 & 34.8 & 33.2 & 56.1 & 47.7 \\
\hline $\begin{array}{l}\text { Time required to discuss colorectal cancer screening } \\
\text { with patients }(n=796)(P=0.9)^{\star}\end{array}$ & 17.0 & 17.0 & 16.9 & 47.1 & 45.6 & 49.5 & 35.9 & 37.4 & 33.5 \\
\hline $\begin{array}{l}\text { Effective communication about patients between the } \\
\text { program and family physicians }(n=794)(P=0.9)^{\star}\end{array}$ & 14.2 & 17.0 & 15.5 & 58.2 & 59.1 & 58.4 & 27.6 & 23.9 & 26.1 \\
\hline
\end{tabular}

Data presented as \%. ${ }^{*} \chi^{2}$ test for differences according to geographical region. Capital (Capital Health Region); CHR (Calgary Health Region); Nonmetro (Nonmetropolitan health regions)

\section{TABLE 4}

Reported wait times for patients referred for colonoscopy according to geographical region (\% of physicians indicating patients referred for colonoscopy wait a specified time)

\begin{tabular}{lccc}
\hline & \multicolumn{3}{c}{ Health region } \\
\cline { 2 - 4 } Type of colonoscopy & CHR & Capital & Nonmetro \\
\hline Screening* & 1.6 & 8.4 & 28.5 \\
<12 weeks & 8.1 & 28.9 & 25.6 \\
3-6 months & 21.7 & 46.2 & 24.9 \\
7-12 months & 68.6 & 16.4 & 21.0 \\
>12 months & 9.5 & 14.7 & 34.9 \\
For follow-up of a positive fecal occult blood test* & & 40.1 \\
<6 weeks & 27.0 & 45.3 & 21.0 \\
7-12 weeks & 43.2 & 36.0 & 4.0 \\
3-6 months & 20.2 & 4.0 & \\
>7 months & & \\
For other reasons (eg, diarrhea, pain, change in bowel habit)* & \\
<6 weeks & 4.6 & 6.2 & 25.5 \\
7-12 weeks & 21.3 & 26.1 & 31.0 \\
3-6 months & 39.2 & 49.6 & 32.9 \\
$7-12$ months & 27.5 & 15.9 & 9.4 \\
$>12$ months & 7.4 & 2.2 & 1.3 \\
\hline
\end{tabular}

${ }^{*} \chi^{2}$ test for differences according to geographical region $(P<0.001)$. Capital (Capital Health Region); CHR(Calgary Health Region); Nonmetro(Nonmetropolitan health regions)

CRC screening to be cost effective. Although this was an improvement from the 2002 survey, it should be noted that $62 \%$ of respondents to the 2008 survey agreed or strongly agreed that inconsistent recommendations make it difficult to decide which tests should be offered to patients. Perceived compliance with recommendations for screening was very similar in the two surveys, with less than one-third of respondents in each survey estimating that at least $75 \%$ of their patients actually complete the recommended screening test.

\section{DISCUSSION}

The findings from the 2008 survey, and comparison with a similar survey in 2002 (23), suggest that screening for CRC is obtaining gradual acceptance among primary care physicians in Alberta. The proportion of primary care physicians who recommend CRC screening has increased; however, patient compliance with screening recommendations is still perceived to be low. Inconsistencies in screening recommendations remain a problem for primary care physicians. A key finding
TABLE 5

Perceived potential barriers to three commonly available colorectal cancer screening tests

\begin{tabular}{|c|c|c|c|}
\hline \multirow[b]{2}{*}{ Potential barriers } & \multicolumn{3}{|c|}{$\begin{array}{l}\text { Physicians who indicated } \\
\text { the following as barriers, } \%\end{array}$} \\
\hline & $\begin{array}{l}\text { Fecal occult } \\
\text { blood test }\end{array}$ & $\begin{array}{c}\text { Flexible } \\
\text { sigmoidoscopy }\end{array}$ & Colonoscopy \\
\hline Patient acceptance* & $56.7-77.4^{\dagger}$ & 65.0 & 87.7 \\
\hline $\begin{array}{l}\text { Low patient acceptance/ } \\
\text { compliance }\end{array}$ & $46.8-67.8^{\dagger}$ & 45.8 & 55.1 \\
\hline $\begin{array}{l}\text { Preparation required by } \\
\text { patient }\end{array}$ & $31.7-51.7^{\dagger}$ & 52.2 & 83.9 \\
\hline Test characteristics* & 89.2 & $58.6-70.0^{\dagger}$ & $59.3-80.0^{\dagger}$ \\
\hline $\begin{array}{l}\text { Potential to miss } \\
\text { cancers (false negatives) }\end{array}$ & 83.4 & 47.8 & 2.9 \\
\hline Too many false positives & $49.4-60.0^{\dagger}$ & 1.1 & $<1$ \\
\hline $\begin{array}{l}\text { Potential for } \\
\text { complications }\end{array}$ & $<1$ & $24.4-39.6^{\dagger}$ & $58.3-78.7^{\dagger}$ \\
\hline $\begin{array}{l}\text { Lack of efficacy } \\
\text { evidence }\end{array}$ & 27.1 & 13.3 & 1.8 \\
\hline Health care resources* & 4.3 & $51.3-69.6^{\dagger}$ & $91.0-97.3^{\dagger}$ \\
\hline Cost to health care system & $<1$ & $20.8-33.5^{\dagger}$ & $64.4-76.5^{\dagger}$ \\
\hline $\begin{array}{l}\text { Availability/ease of } \\
\text { access for patients }\end{array}$ & 4.2 & $37.8-56.1^{\dagger}$ & $70.5-80.4^{\dagger}$ \\
\hline Long wait times & $<1$ & $32.7-47.4^{\dagger}$ & $80.8-95.4^{\dagger}$ \\
\hline
\end{tabular}

of the present descriptive study was the regional variation in practices, perceived barriers and concerns regarding provincial population-based screening programs based on the FOBT as the primary screening test.

Qualitative and mixed methods studies $(24,25)$ have found that physician perception of patient noncompliance with a recommendation for screening is a barrier to CRC screening. Our findings suggest that educational resources for patients are needed, particularly practice-based print resources and Internet sites that physicians can refer patients to. Education programs for the general public about the importance of CRC screening may also be needed to address physician concerns about the general lack of awareness and knowledge about CRC screening.

The increasing use of colonoscopy as a primary screening test for CRC (26), particularly in light of the 2008 United States 
Preventive Services Task Force recommendations (9) that include - for the first time - colonoscopy as one of the acceptable screening tests for CRC, creates challenges for FOBT-based provincial screening programs. Indeed, since the 2002 Alberta survey, the release of Canadian guidelines recommending choices for testing by the Canadian Association of Gastroenterology (13) and the Alberta Clinical Practice Guidelines Program (14), in addition to the American guidelines (12), may make acceptance of provincial programs based on FOBT as the primary screening test more difficult to implement. The different perspectives between population-based programs that recommend a single test versus clinical practice guidelines that support a range of screening options creates a dilemma for primary care physicians and can lead to mixed messages for the public. The issue is complicated by the differing ability of various screening tests to detect adenomatous polyps and, hence, reduce incidence in addition to mortality from CRC (12). While public education often seeks to provide consistent and simple messages, it may be challenging to define common key messages about expectations for CRC screening when comparing programs based on nonrehydrated guaiac FOBTs compared with programs offering screening colonoscopy.

Remaining major barriers to FOBTs include the potential to miss cancers, patient acceptance and concern about too many false positives. Patient acceptance is a concern for all types of testing but is particularly important for FOBT, for which efficacy is based on adherence to repeated testing at annual or biennial intervals (27). The perceived lack of efficacy evidence for FOBT remains a barrier, although less so than in the 2002 survey (23). The lack of concern regarding colonoscopy efficacy may also need to be addressed in light of evidence suggesting - as practiced in the community - that it may be less efficacious in reducing CRC mortality than previously believed $(28,29)$. Wait times for diagnostic colonoscopy may increase as screening rates increase, particularly in regions such as the CHR where colonoscopy is more commonly recommended as a primary screening test by physicians. Several US studies have found CRC screening rates to vary with regional differences in the screening practices of primary care physicians (30) and within urban centres (31), and between states (32). Practice audits in Canada (33) found that the percentage of gastroenterologists who offer screening colonoscopy to average-risk patients varied from $29 \%$ to $100 \%$ across provinces (national average $78 \%$ ). Alberta (at $83 \%$ ) was close to the national average. Wait times for colonoscopy were longer for gastroenterologists who provided screening colonoscopies for average-risk patients, with total median wait times of 99 days and 66 days, respectively, between those who offered average-risk screening versus those who did not.

Endoscopic capacity for follow-up of a positive FOBT is a major concern among all physicians and has been identified as a major concern in implementing population-based CRC screening programs in Canada (34). A recent national practice audit of Canadian gastroenterologists (35) reported a median of 73 days from referral to investigation for patients with a positive FOBT, which exceeded the consensus benchmark wait time of two months. Access to colonoscopy will become even more important as rates of screening increase, and routine surveillance of polyps identified at colonoscopy also demand colonoscopy resources $(36,37)$. High adherence

\section{TABLE 6}

Comparison of opinions and colorectal cancer (CRC) screening practices between the 2002 and 2008 surveys

\begin{tabular}{|c|c|c|}
\hline \multicolumn{3}{|l|}{ Opinions regarding CRC screening } \\
\hline \multirow[b]{2}{*}{ Physicians who strongly agree/agree with statement, \% } & \multicolumn{2}{|c|}{ Survey year } \\
\hline & 2008 & 2002 \\
\hline $\begin{array}{l}\text { I am convinced CRC screening is beneficial for my } \\
\text { patients }\end{array}$ & 95 & 73 \\
\hline $\begin{array}{l}\text { I have enough knowledge to explain pros and cons } \\
\text { of various CRC screening tests to my patients }\end{array}$ & 80 & 65 \\
\hline Screening for CRC is cost effective & 64 & 37 \\
\hline $\begin{array}{l}\text { Inconsistent recommendations make it difficult to } \\
\text { decide which tests should be offered to patients }\end{array}$ & 62 & 82 \\
\hline \multicolumn{3}{|l|}{ Colorectal cancer screening practices, $\%$} \\
\hline Recommend average-risk patients be screened & 96 & 75 \\
\hline Start screening at 50 to 59 years of age & 84 & 69 \\
\hline \multicolumn{3}{|l|}{ Recommend screening to $>75 \%$ of patients } \\
\hline Calgary Health Region & 71 & 39 \\
\hline Capital Health Region & 68 & 36 \\
\hline Nonmetropolitan health regions & 57 & 32 \\
\hline \multicolumn{3}{|c|}{$\begin{array}{l}\text { Estimated percentage of patients who comply with screening } \\
\text { recommendations, \% }\end{array}$} \\
\hline$<25 \%$ & 5 & 11 \\
\hline $25 \%$ to $49 \%$ & 15 & 18 \\
\hline $50 \%$ to $74 \%$ & 32 & 28 \\
\hline$\geq 75 \%$ & 32 & 28 \\
\hline Do not know & 16 & 15 \\
\hline
\end{tabular}

to colonoscopic follow-up of patients with a positive FOBT is necessary to achieve the mortality reductions seen in randomized controlled trials and is an important component of organized population-based screening programs (38). Clearly, screening programs will need to convince physicians that there is adequate capacity for endoscopic follow-up of positive FOBTs if population-based programs based on FOBT are to be widely accepted.

Our study was limited by its cross-sectional design. It is not possible to ascertain the influence of the various clinical practice guidelines, or the announcement of the provincial CRC screening program on physician CRC screening opinions and practices. The data on screening practices are based on selfreports, which may over- or underestimate actual practices (39). Our response rate was similar to those typically attained in large mailed surveys of physicians (40) and of surveys of Canadian physicians regarding other cancer screening tests $(41,42)$. Selection bias remains a possibility, although respondents did not differ from nonrespondents in terms of geographical location of practice, sex and College of Family Physicians of Canada training. A review of physician surveys comparing early versus late responders (a proxy for nonresponders) found few differences in demographic factors, suggesting nonresponse bias may be less important in physician surveys than in surveys of the general public (43).

\section{CONCLUSION}

Physician attitudes toward CRC screening have improved over the past six years, and the majority of primary care physicians recommend screening for average-risk patients. Concerns regarding FOBT-based provincial screening programs have been identified and barriers exist to all screening methods. Colonoscopy remains the screening test that the majority of 
physicians in our study would choose for themselves, and its use as a primary screening test for patients is increasing. Provincial programs will need to address the issue of endoscopic capacity and barriers to FOBT to gain primary care physician adherence to programs based on FOBT as the primary screening test. Public education programs and educational resources for patients may assist in this process. The findings of regional variation in practices and barriers highlight the need for provincial programs to work with communities of physicians to address regional concerns.

\section{REFERENCES}

1. Canadian Cancer Society's Steering Committee. Canadian Cancer Statistics 2009. Toronto, Canadian Cancer Society, 2009.

2. Shapiro JA, Seeff LC, Thompson TD, Nadel MR, Klabunde CN, Vernon SW. Colorectal cancer test use from the 2005 National Health Interview Survey. Cancer Epidemiol Biomarkers Prev 2008;17:1623-30.

3. McGregor SE, Hilsden RJ, Li FX, Bryant HE, Murray A. Low uptake of colorectal cancer screening $3 \mathrm{yr}$ after release of national recommendations for screening. Am J Gastroenterol 2007;102:1727-35.

4. Rabeneck L, Paszat LF. A population-based estimate of the extent of colorectal cancer screening in Ontario. Am J Gastroenterol 2004;99:1141-4.

5. Wilkins K, Shields M. Colorectal cancer testing in Canada - 2008. Health Rep 2009;20:1-10.

6. Maciosek MV, Solberg LI, Coffield AB, Edwards NM, Goodman MJ. Colorectal cancer screening: Health impact and cost effectiveness. Am J Prev Med 2006;31:80-9.

7. Maciosek MV, Coffield AB, Edwards NM, Flottemesch TJ, Goodman MJ, Solberg LI. Priorities among effective clinical preventive services: Results of a systematic review and analysis. Am J Prev Med 2006;31:52-61.

8. U.S. Preventive Services Task Force. Screening for colorectal cancer: Recommendation and rationale. Ann Intern Med 2002;137:129-31.

9. Screening for colorectal cancer. U.S. Preventive Services Task Force recommendation statement. Ann Intern Med 2008;149:627-37.

10. Canadian Task Force on Preventive Health Care. Colorectal cancer screening. Recommendation statement from the Canadian Task Force on Preventive Health Care. CMAJ 2001;165:206-8.

11. Winawer S, Fletcher R, Rex D, et al. Colorectal cancer screening and surveillance. Clinical guidelines and rationale - update based on new evidence. Gastroenterology 2003;124:544-60.

12. Levin B, Lieberman DA, McFarland B, et al. Screening and surveillance for the early detection of colorectal cancer and adenomatous polyps, 2008: A joint guideline from the American Cancer Society, the US Multi-Society Task Force on Colorectal Cancer, and the American College of Radiology. Gastroenterology 2008;134:1570-95.

13. Leddin D, Hunt R, Champion M, Cockeram A, Flook N; Canadian Association of Gastroenterology and the Canadian Digestive Health Foundation. Guidelines on colon cancer screening. Can J Gastroenterol 2004;18:93-9.

14. Screening for colorectal cancer. Clinical Practice Guidelines 2008. Toward Optimized Practice. Edmonton, Alberta. <http://www. topalbertadoctors.org/PDF/complete\%20set/Colorectal\%20Cancer/ colorectal_guideline.pdf> (Accessed on July 21, 2009).

15. Coombs A, Jones-McLean E, Le-Petit C, et al. Technical report for the National Committee on Colorectal Cancer Screening. Health Canada, 2002:1-136.

16. Ling BS, Klein WM, Dang Q. Relationship of communication and information measures to colorectal cancer screening utilization: Results from HINTS. J Health Commun 2006;(Suppl 1):181-90.

17. Seeff LC, Nadel MR, Klabunde CN, et al. Patterns and predictors of colorectal cancer test use in the adult U.S. population. Cancer 2004;100:2093-103.

18. Klabunde CN, Vernon SW, Nadel MR, Breen N, Seeff LC, Brown ML. Barriers to colorectal cancer screening: A comparison of reports from primary care physicians and average-risk adults. Med Care 2005;43:939-44.

19. Zapka JG, Puleo E, Vickers-Lahti M, Luckmann R. Healthcare system factors and colorectal cancer screening. Am J Prev Med 2002;23:28-35.

20. Colorectal cancer screening. Recommendation statement from the Canadian Task Force on Preventive Health Care. Can Fam Physician 2001;47:1811-3,1815.

21. Schabas RE. Colorectal cancer screening in Canada: It's time to act. CMAJ 2003;168:178-9.

22. Winawer SJ, Fletcher RH, Miller L, et al. Colorectal cancer screening: Clinical guidelines and rationale. Gastroenterology 1997;112:594-642.

23. McGregor SE, Hilsden RJ, Murray A, Bryant HE. Colorectal cancer screening: Practices and opinions of primary care physicians. Prev Med 2004:39:279-85.

24. Levy BT, Nordin T, Sinift S, Rosenbaum M, James PA. Why hasn't this patient been screened for colon cancer? An Iowa Research Network study. J Am Board Fam Med 2007;20:458-68.

25. Guerra CE, Schwartz JS, Armstrong K, Brown JS, Halbert CH, Shea JA. Barriers of and facilitators to physician recommendation of colorectal cancer screening. J Gen Intern Med 2007;22:1681-8.

26. Phillips KA, Liang SY, Ladabaum U, et al. Trends in colonoscopy for colorectal cancer screening. Med Care 2007;45:160-7.

27. Lieberman D. Screening, surveillance, and prevention of colorectal cancer. Gastrointest Endosc Clin North Am 2008;18:595-605.

28. Baxter NN, Goldwasser MA, Paszat LF, Saskin R, Urbach DR, Rabeneck L. Association of colonoscopy and death from colorectal cancer. Ann Intern Med 2009;150:1-8.

29. Ransohoff DF. How much does colonoscopy reduce colon cancer mortality? Ann Intern Med 2009;150:50-2.

30. Haas JS, Fitzmaurice G, Brawarsky P, et al. Association of regional variation in primary care physicians' colorectal cancer screening recommendations with individual use of colorectal cancer screening. Prev Chronic Dis 2007;4:A90.

31. Gorin SS, Ashford AR, Lantigua R, et al. Intraurban influences on physician colorectal cancer screening practices. J Natl Med Assoc 2007;99:1371-80.

32. Cooper GS, Koroukian SM. Geographic variation among Medicare beneficiaries in the use of colorectal carcinoma screening procedures. Am J Gastroenterol 2004;99:1544-50.

33. Armstrong D, Barkun AN, Chen Y, et al. Access to specialist gastroenterology care in Canada: The Practice Audit in Gastroenterology (PAGE) Wait Times Program. Can J Gastroenterol 2008;22:155-60.

34. Moayyedi P, Tepper J, Hilsden R, Rabeneck L. International comparisons of manpower in gastroenterology. Am J Gastroenterol 2007;102:478-81.

35. Leddin D, Armstrong D, Barkun AN, et al. Access to specialist gastroenterology care in Canada: Comparison of wait times and consensus targets. Can J Gastroenterol 2008;22:161-7.

36. Mysliwiec PA, Brown ML, Klabunde CN, Ransohoff DF. Are physicians doing too much colonoscopy? A national survey of colorectal surveillance after polypectomy. Ann Intern Med 2004;141:264-71.

37. Krist AH, Jones RM, Woolf SH, et al. Timing of repeat colonoscopy: Disparity between guidelines and endoscopists' recommendation. Am J Prev Med 2007;33:471-8.

38. Nadel MR, Shapiro JA, Klabunde CN, et al. A national survey of primary care physicians' methods for screening for fecal occult blood. Ann Intern Med 2005;142:86-94.

39. Montano DE, Phillips WR. Cancer screening by primary care physicians: A comparison of rates obtained from physician self-report, patient survey, and chart audit. Am J Public Health 1995;85:795-800.

40. Cummings SM, Savitz LA, Konrad TR. Reported response rates to mailed physician questionnaires. Health Serv Res 2001;35:1347-55.

41. Gray RE, Carroll J, Goel V, et al. Canadian family physicians and prostate cancer: A national survey. Can J Urol 1999;6:892-7.

42. Abdel-Malek N, Chiarelli AM, Sloan M, Stewart DE, Mai V, Howlett RI. Influence of physician and patient characteristics on adherence to breast cancer screening recommendations. Eur J Cancer Prev 2008;17:48-53.

43. Kellerman SE, Herold J. Physician response to surveys. A review of the literature. Am J Prev Med 2001;20:61-7. 


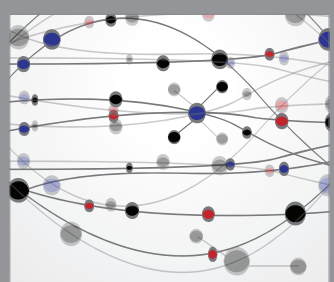

The Scientific World Journal
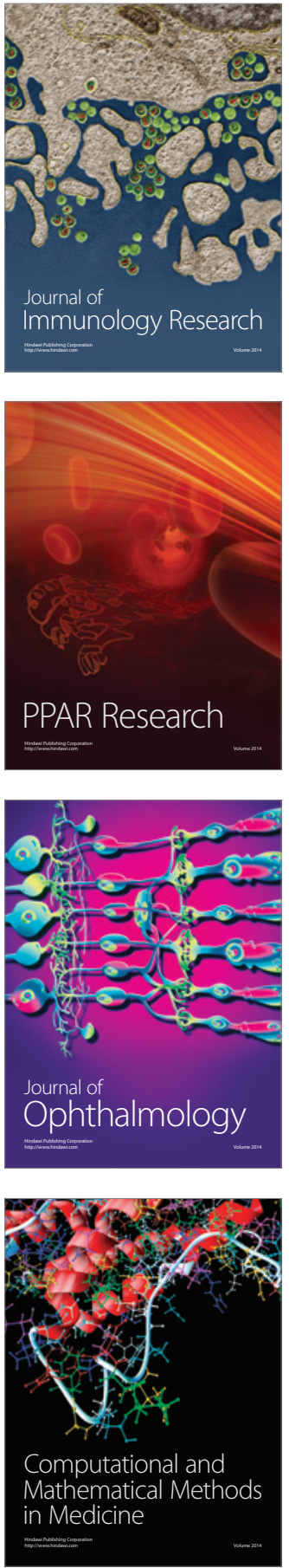

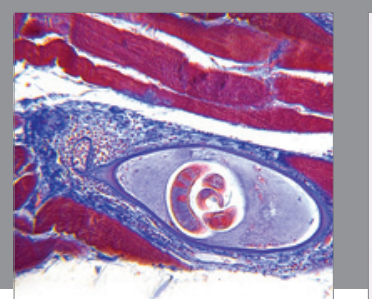

Gastroenterology Research and Practice

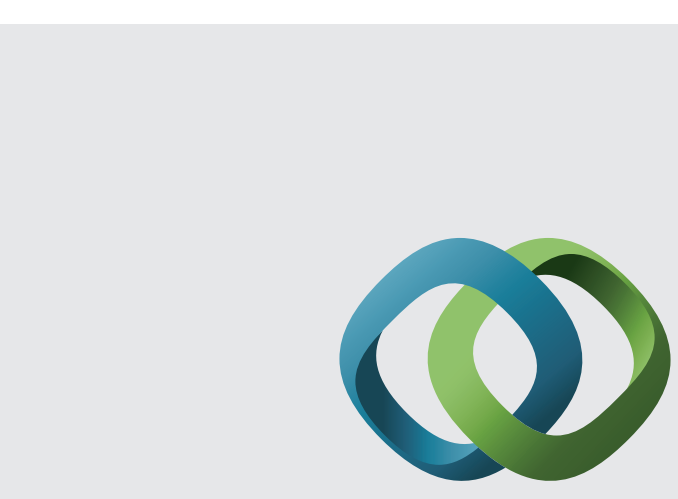

\section{Hindawi}

Submit your manuscripts at

http://www.hindawi.com
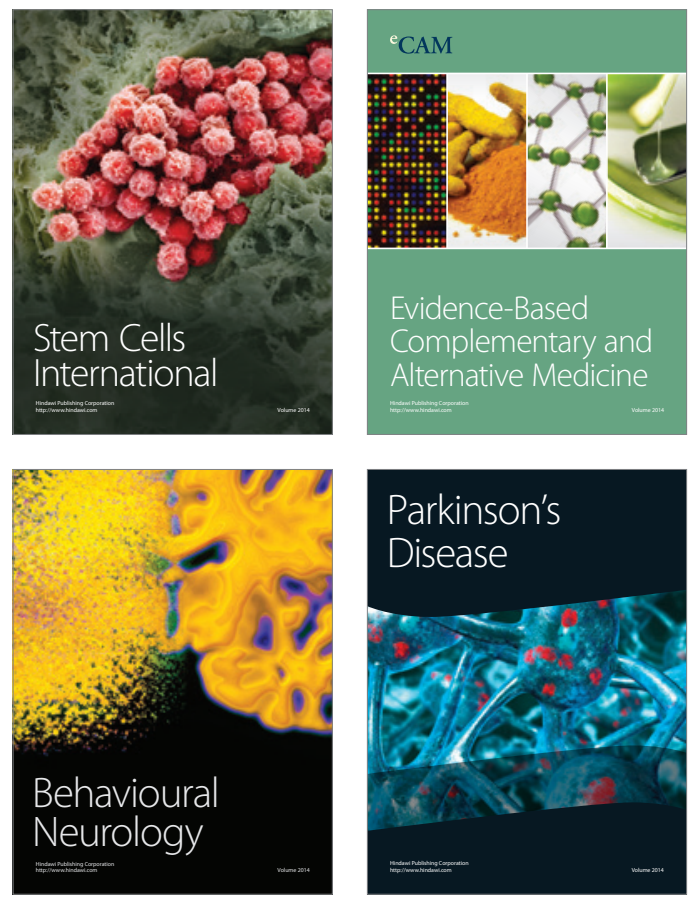
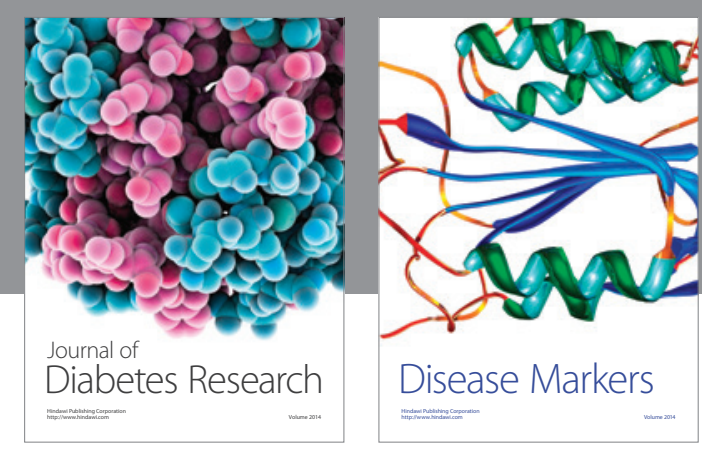

Disease Markers
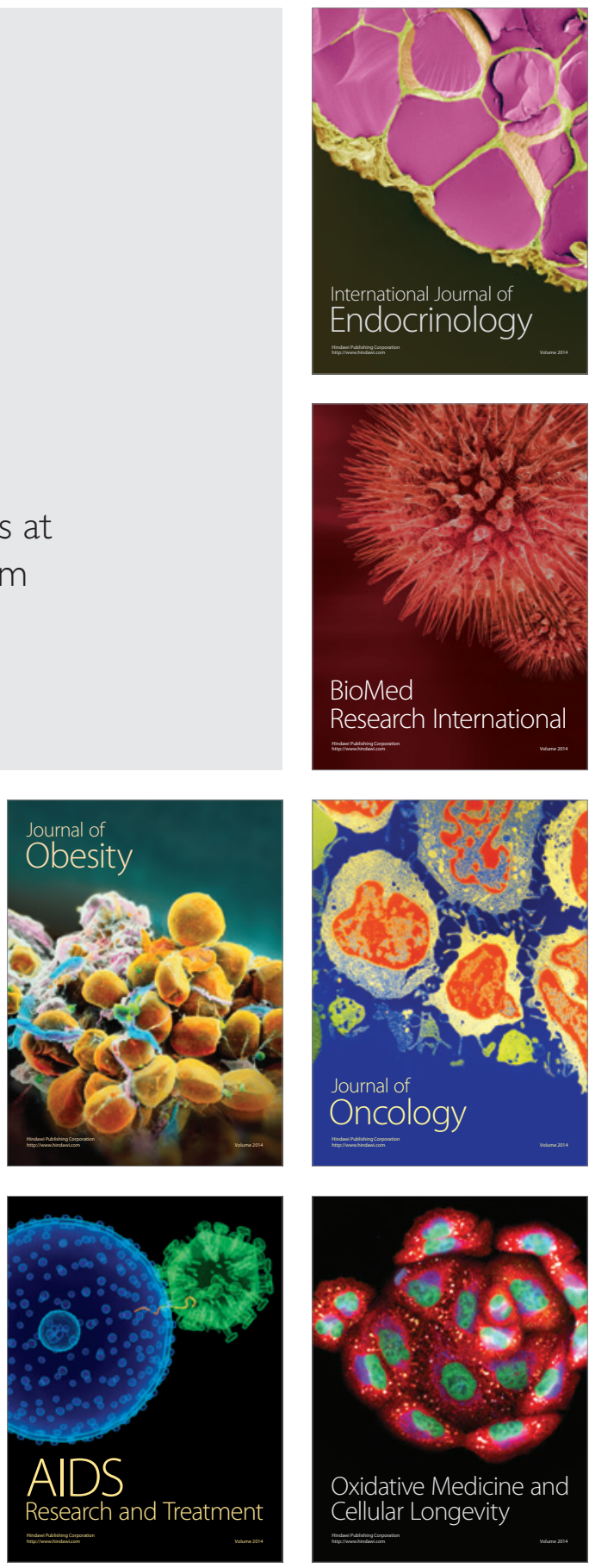